CASE REPORT

\title{
Mixed Type Mucinous and Infiltrating Ductal Carcinoma: A Rare Form of Male Breast Cancer
}

\author{
Pugazharasan Mannarmannan ${ }^{1}$, Saravanakumar Subbaraj ${ }^{2}$, Tirou A Tirougnanassambandamourty ${ }^{3}$
}

\begin{abstract} and infiltrating ductal type in a male breast carcinoma.

Keywords: Carcinoma, Infiltrating ductal, Male breast carcinoma, Mucinous carcinoma.

\section{INTRODUCTION}

Incidence of male breast carcinoma is rare $(<1 \%) .{ }^{1}$ Mucinous carcinoma is a less common histological variant in $1-4 \%$ of breast cancer. ${ }^{2}$ Very few cases were reported in literature about the incidence of male breast carcinoma and the histological variant of mucinous type. This mucinous type has two distinct subtypes based on tumor cellularity, pure or mixed mucinous. It is more common in postmenopausal women of age over 60 years. It has good prognosis. We are presenting a case of mixed type of male breast carcinoma.
\end{abstract}

The major invasive tumor types of carcinoma breast include infiltrating ductal, invasive lobular, ductal/lobular, mucinous (colloid), tubular, medullary and papillary carcinomas. Of these, infiltrating ductal carcinoma (IDC) is, by far, the most common subtype accounting for 70-80\% of all invasive lesions. Combination of more than one pathological form is a very rare phenomenon. Here, we present such mixed mucinous

SBV Journal of Basic, Clinical and Applied Health Science (2019): 10.5005/jp-journals-10082-02201

\section{Case Description}

A 60-year old male presented with painless swelling over the left side nipple areolar region for 1 month which progressively increased in size. No history of nipple discharge. Patient gave history of right orchidectomy for pyocele 3 years back. Examination findings showed a mobile nontender swelling of size $4 \times 3 \mathrm{~cm}$ in the left nipple areolar complex with skin fixity with significant hard mobile left axillary lymphadenopathy (Fig. 1).

FNAC of left breast showed highly cellular smear with scattered and loosely cohesive clusters of pleomorphic cells showing hyperchromatic nucleus and anisonucleosis. Occasional cells with

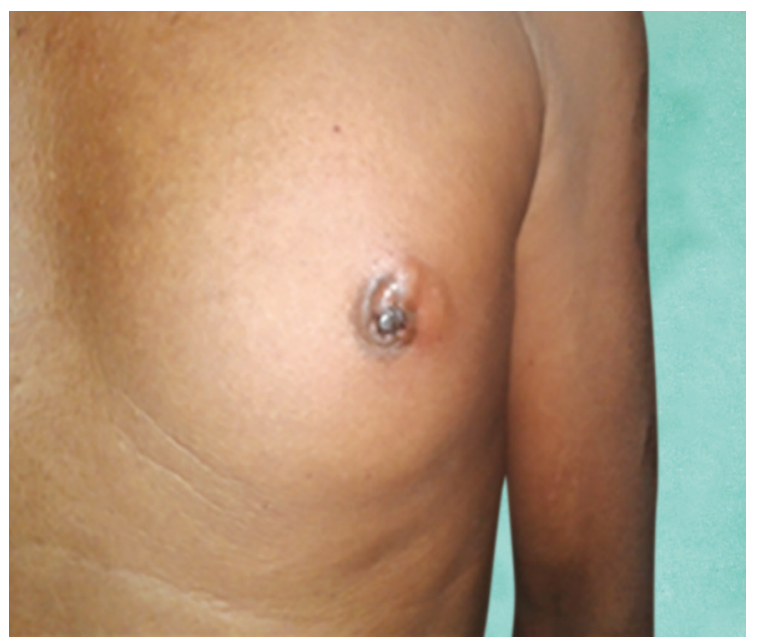

Fig. 1: Swelling of left nipple areola complex with skin involvement
${ }^{1-3}$ Department of Surgery, Mahatma Gandhi Medical College and Research Institute, Sri Balaji Vidyapeeth, Puducherry, India

Corresponding Author: Saravanakumar Subbaraj, Department of Surgery, Mahatma Gandhi Medical College and Research Institute, Sri Balaji Vidyapeeth, Puducherry, India, Phone: +91 9443996507, e-mail: drsksurgeon@gmail.com

How to cite this article: Mannarmannan P, Subbaraj S, Tirougnanassambandamourty TA. Mixed Type Mucinous and Infiltrating Ductal Carcinoma: A Rare Form of Male Breast Cancer. J Basic Clin Appl Health Sci 2019;2(2):81-82.

Source of support: Nil

Conflict of interest: None

prominent nucleoli with few cyst macrophages and occasional tumor giant cells in hemorrhagic background. Impression was carcinoma left breast.

FNAC of left axilla showed highly cellular smear showing clusters of epithelial cells with similar morphology as described above in lymphoid background. Impression of metastatic deposit in left axillary node was entertained.

Patient underwent modified radical mastectomy under general anesthesia. HPE revealed mixed type mucinous (60\%) and infiltrating ductal carcinoma (40\%) - grade II carcinoma left breast with involvement of nipple areola complex (Fig. 2). All surgical margins are free of tumor. Two out of seven lymph nodes showed metastasis. Patient received adjuvant chemotherapy and radiotherapy and on regular follow-up.

\section{Discussion}

The infiltrative ductal carcinoma is the most common and mucinous carcinoma of breast is a rare. It is commonly found in postmenopausal women of age above 60 years. ${ }^{3}$ It is characterized into two types: (i) pure and (ii) mixed type. About $2-3 \%$ comprise of pure types in which abnormal cancer cells are surrounded by pool of mucin and $5 \%$ of invasive ductal carcinoma have mucin within them. Literature states, it is more common in postmenopausal women and has better prognosis. ${ }^{4,5}$ Lymph nodal metastasis is uncommon. This type of cancer is extremely rare in men. Primary treatment is surgery with postoperative adjuvant treatment: radiotherapy,

o The Author(s). 2019 Open Access This article is distributed under the terms of the Creative Commons Attribution 4.0 International License (https://creativecommons. org/licenses/by-nc/4.0/), which permits unrestricted use, distribution, and non-commercial reproduction in any medium, provided you give appropriate credit to the original author(s) and the source, provide a link to the Creative Commons license, and indicate if changes were made. The Creative Commons Public Domain Dedication waiver (http://creativecommons.org/publicdomain/zero/1.0/) applies to the data made available in this article, unless otherwise stated. 

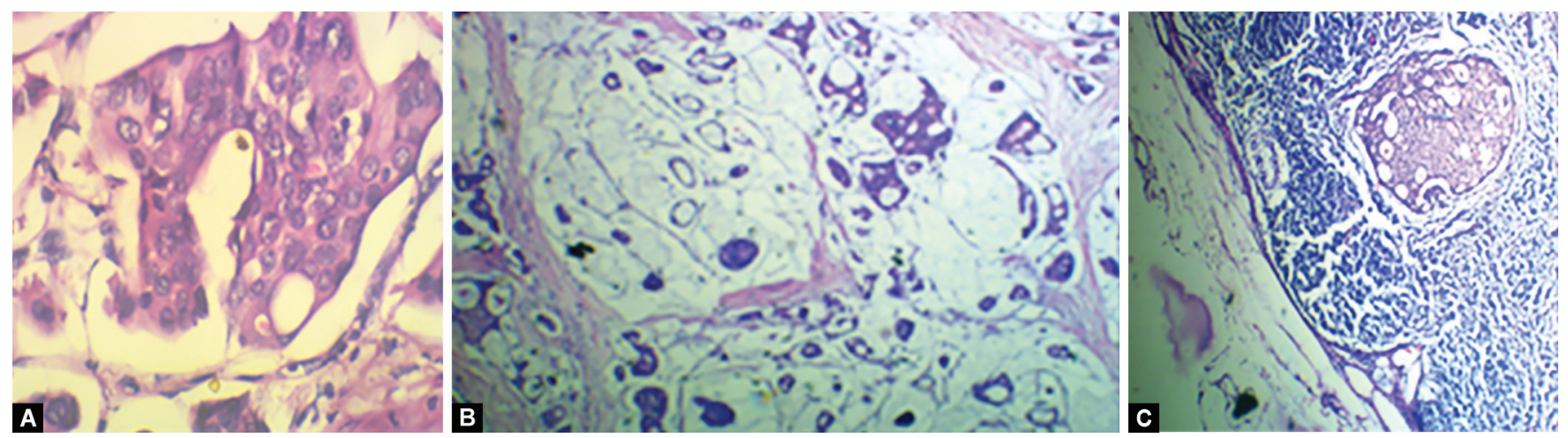

Figs $2 \mathrm{~A}$ to $\mathrm{C}$ : Microscopy shows both mucinous and infiltrating ductal pattern

chemotherapy and endocrine therapy. Almost all mucinous carcinomas are found to be estrogen receptor (ER) and progesterone receptor (PR) positive and hence hormone therapy is an optimal adjuvant. ${ }^{6}$ In men, primary treatment is surgery with postoperative adjuvant as practised for women.

\section{ConcLusion}

Incidence of carcinoma of the male breast is rare as mentioned above. The most common pathological form of invasive cancer is infiltrating ductal carcinoma. Mixed mucinous carcinoma with infiltrating ductal carcinoma in a carcinoma male breast is a very rare entity. Treatment of such mixed types depends on the subtype, size, lymph node involvement and the hormonal status. Early diagnosis and the treatment have good prognosis, with survival rate up to 10 years in $50 \%$ of cases.

\section{Acknowledgment}

I thank the Department of Pathology for providing report and images.

\section{References}

1. Bae SY, Choi MY, Cho DH, Lee JE, Nam SJ, Yang JH. Mucinous carcinoma of the breast in comparison with invasive ductal carcinoma: clinicopathologic characteristics and prognosis. J Breast Cancer 2011;14:308-313. DOI: 10.4048/jbc.2011.14.4.308.

2. Anderson WF, Chu KC, Chang S, Sherman ME. Comparison of agespecific incidence rate patterns for different histopathologic types of breast carcinoma. Cancer Epidemiol Biomarkers Prev 2004;13: 1128-1135.

3. Hanagiri T, Ono K, Baba T, So T, Yamasaki M, Nagata $Y$, et al. Clinicopathologic characteristics of mucinous carcinoma of the breast. Int Surg 2010;95:126-129.

4. Di Saverio S, Gutierrez J, Avisar E. A retrospective review with long term follow up of 11,400 cases of pure mucinous breast carcinoma. Breast Cancer Res Treat 2008;111:541-547. DOI: 10.1007/s10549-0079809-z.

5. Park S, Koo J, Kim JH, Yang WI, Park BW, Lee KS. Clinicopathological characteristics of mucinous carcinoma of the breast in Korea: comparison with invasive ductal carcinoma-not otherwise specified. J Korean Med Sci 2010;25:361-368. DOI: 10.3346/jkms.2010.25.3.361.

6. LiCl. Risk of mortality by histologic type of breast cancer in the United States. Horm Cancer 2010;1:156-165. DOI: 10.1007/s12672-010-0016-8. 